$\beta, \gamma, \gamma^{\prime}=$ integral constants

$\delta, \delta^{\prime}=$ integral constants

$\langle$ Suffix $\rangle$

$1,2=$ directions for $x>0$ and $x \leq 0$ respectively

$\mathrm{A}, \mathrm{B}=$ molecules of $\mathrm{A}$ and $\mathrm{B}$ respectively

I, II = at the evaporating and condensing surfaces respectively

$\mathrm{s} \quad=$ saturated value

$\mathrm{t}=$ total value
Literature cited

1) Uyeha, H., T. Kajiura and O. Yoshikawa: Kagaku Kögaku (Chem. Eng., Japan) 24, 5, 274 (1960)

2) Sherwood, T. K. and N. E. Cooke: A.I.Ch.E. Journal, $3,37(1957)$

3) Toei, R., M. Okazaki, A. Uragami and Y. Takaki: J.Ch. Eng. of Japan 1, 2, 125 (1968)

4) to be published

\title{
LONGITUDINAL DISPERSION OF GAS IN A MOVING BED AT LOW REYNOLDS NUMBERS*
}

\author{
SOK MOON YOON** AND DAIZO KUNII \\ Department of Chemical Engineering, University of Tokyo, \\ Tokyo, Japan
}

\begin{abstract}
Employing two kinds of fine glass keads at low Reynolds numbers, the longitudinal dispersion coefficients of gas were measured in a moving bed by analyzing the response curves measured at two downsiream points of a bed. The dispersion data obtained in a moving bed were comparable with the results investigated by Carberry and Bretton ${ }^{3}$ in a packed bed for the same sysiem of helium-air. The effect of solid velocities on the gas mixing was not so favorable, and the concept of tortuosity factor was acceptable to describe the discrepancy of the data with the molecular diffusivity at low Reynolds numbers.
\end{abstract}

According to the best of the authors' knowledge, studies of the mixing of fluids in moving beds are very few, and the only available data were obtained by Muchi et al. ${ }^{10}$. Applying the methods developed by Gilliland and Mason ${ }^{7,8)}$, Muchi et al. measured the longitudinal dispersion coefficients of gas and liquids. They also measured the radial dispersion coefficients of gas by the procedure given by Hanratty et al.9). The data of Muchi et al. show that the dispersion coefficients increase regularly with the velocities of solids as well as that of gas.

Generally, from the macro point of view, rodlike flow of solids in a moving bed is assumed. In actual moving beds, however, the solids may move downward with undulation, and the voids alternately expand and contract. Therefore it is supposed that the fluid mixing is affected not by the solids velocity itself but by the pattern of moving solids, which consequently varies with the solids velocity.

Employing the same apparatus and glass beads as used in the experiments described in our previous paper ${ }^{13)}$, an experimental investigation was carried out to measure the longitudinal dispersion coefficients $E_{x}$ to check the effect of the moving solids, and to compare them with the data for packed beds at low Reynolds numbers.

* Received on September 9, 1970

** Mobil Sekiyu Kabushiki Kaisha, Tokyo

\section{Experiments}

According to the authors' paper ${ }^{13)}$, pressure drop through a moving bed is originated by the slip velocity between the gas flow and the descending solids, and the flowing gas measured at the outlet of a bed is not exactly the same as the flowing gas through the test section. With high descending velocity of fine solids, gas may flow downward against the higher pressure at the bottom of the bed. Considering this information, interstitial gas velocities were determined for the various solids velocities under constant pressure drop.

Helium, which was steadily introduced into the middle part of a moving bed of glass beads was stopped instantaneously, and the concentration time curves (I curves) were measured by thermal conductivity cells. Two sets of response curves taken $20 \mathrm{~cm}$ apart were obtained. Errors due to the end effects were thereby eliminated.

\section{Results and Discussion}

After differentiating the I curves numerically, the variances of the concentration distributions were evaluated. If each pair of response curves was obtained at two positions (denoted suffixes 1 and 2) at some distance apart in an infinite bed, the following simple 


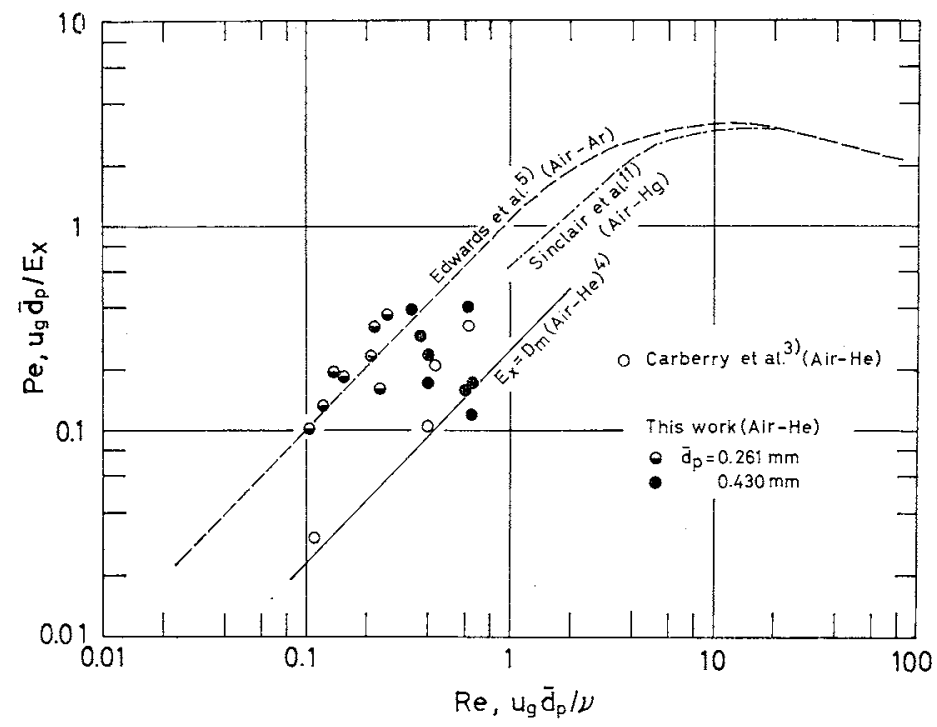

Fig. 1 Comparison of results with those of packed beds

\begin{tabular}{|c|c|c|c|c|}
\hline $\begin{array}{c}\bar{d}_{p} \\
{[\mathrm{~mm}]}\end{array}$ & $\begin{array}{c}\Delta P \\
{\left[\mathrm{gr} / \mathrm{cm}^{3}\right]}\end{array}$ & $\begin{array}{c}u_{s} \\
{[\mathrm{~cm} / \mathrm{sec}]}\end{array}$ & $\begin{array}{c}u_{g} \\
{[\mathrm{~cm} / \mathrm{sec}]}\end{array}$ & $\begin{array}{c}E_{x} \\
{\left[\mathrm{~cm}^{2} / \mathrm{sec}\right]}\end{array}$ \\
\hline \multirow{8}{*}{$\begin{array}{c}0.261 \\
(\varepsilon=0.367)\end{array}$} & 0.125 & 0 & 0.899 & 0.161 \\
\hline & "I & 0.087 & 0.796 & 0.105 \\
\hline & $"$ & 0.193 & 0.695 & 0.138 \\
\hline & 11 & 0.361 & 0.501 & 0.127 \\
\hline & 0.195 & 0 & 1.458 & 0.103 \\
\hline & "I & 0.131 & 1.332 & 0.217 \\
\hline & " & 0.179 & 1.253 & 0.103 \\
\hline & $" 1$ & 0.250 & 1.207 & 0.138 \\
\hline \multirow{8}{*}{$\begin{array}{c}0.430 \\
(\varepsilon=0.375)\end{array}$} & 0.054 & 0.143 & 1.405 & 0.258 \\
\hline & II & 0.144 & 1.403 & 0.350 \\
\hline & "I & 0.277 & 1.269 & 0.187 \\
\hline & "I & 0.394 & 1.149 & 0.127 \\
\hline & 0.084 & 0.235 & 2.187 & 0.235 \\
\hline & 0.086 & 0.138 & 2.315 & 0.575 \\
\hline & 0.088 & 0.236 & 2.269 & 0.830 \\
\hline & "I & 0.387 & 2.120 & 0.582 \\
\hline
\end{tabular}

relationship was given by Aris ${ }^{1)}$.

$$
\begin{aligned}
& \Delta \sigma_{t}{ }^{2}=\left(\sigma_{i}{ }^{2}\right)_{2}-\left(\sigma_{t}{ }^{2}\right)_{1} \\
& \Delta \sigma=\Delta \sigma_{t}{ }^{2} / \vec{t}^{2}=2 E_{x} / u_{g} \Delta x
\end{aligned}
$$

The longitudinal dispersion coefficients $E_{x}$ were evaluated by Eq.(2) for various velocities of gas and solids, and are presented in Table 1. The results are plotted as Peclet numbers vs. Reynolds numbers as shown in Fig. 1. The data are so scattered that the effect of the descending velocity of solids cannot be clarified.

In Fig. 1 the results in a moving bed are compared with those of other workers who have measured gas dispersion in packed beds at low Reynolds numbers. The molecular diffusivity of air-helium $\left(0.706 \mathrm{~cm}^{2} / \mathrm{sec}\right)$ is given in the reference ${ }^{4)}$ and this is also compared in Fig. 1.

Carberry and Bretton ${ }^{3\rangle}$ injected pulses of air into helium in a chromatographic column and obtained the results that $E_{x}$ was approximately 0.67 times $D_{m}$ at $1>R e$. Sinclair and Potter ${ }^{11}$ ) used a frequency response technique of mercury vapor applied to the flow of air through beds of ballotini in a medium range of Reynolds numbers (1 30). Edwards and Richardson ${ }^{5}$ injected a pulse of argon into air stream in packed beds of glass beads and obtained $E_{x}$ for a wide range of Reynolds numbers $(0.02 \sim 140)$. Recently Urban and Gomezplata ${ }^{12)}$ studied the longitudinal dispersion in packed beds for $0.15<R e<150$, and indicated apparent dependence of the particle diameter at $R e>1.5$ which had not been observed by earlier investigators.

Edwards and Richardson ${ }^{5)}$ and Evans and Kenney') have discussed the operation of molecular diffusion in a packed bed and have pointed out that its contribution to longitudinal dispersion is reduced by virtue of the tortuous nature of the passages between the particles. Thus, if molecular diffusion is the controlling mechanism, the longitudinal dispersion coefficient is related to the molecular diffusivity by $E_{x}=\tau D_{m}$, where $\tau$ is known as the tortuosity factor.

The results of the investigation by Carberry et al. gives $\tau=0.64$, the work of Edwards et al. gives $\tau=0.69$. Referring to Fig. 1, if the concept of tortuosity factor is adopted, the longitudinal dispersion data in a moving bed are in good agreement with those measured by Carberry et al. in a packed bed for the same gas system.

\section{Nomenclature}

$D_{m_{b}}=$ molecular diffusivity

$\bar{d}_{p}=$ average particle diameter

$E_{X}=$ longitudinal dispersion coefficient

$P=$ pressure drop

$P e=$ Peclet number, $\frac{u_{g} \bar{d}_{p}}{E_{X}}$

$\left[\mathrm{cm}^{2} / \mathrm{sec}\right]$ $[\mathrm{cm}]$ $\left[\mathrm{cm}^{2} / \mathrm{sec}\right]$ $\left[\mathrm{gr} / \mathrm{cm}^{3}\right]$

$R e=$ Reynolds number, $\frac{u_{g} \bar{d}_{p}}{\nu}$

$t=$ first moment of response curves or mean residence time of gas

$u_{g}=$ linear interstitial gas velocity

$u_{s}=$ descending velocity of solids

$x=$ longitudinal distance

$\Delta \sigma=$ defined by Eq.(2)

$\sigma_{t}{ }^{2}=$ second moment or variance of response curves 
$\begin{aligned} \nu & =\text { kinetic viscosity } \\ \tau & =\text { tortuosity }\end{aligned}$

$\left[\mathrm{cm}^{2} / \mathrm{sec}\right.$ $[-]$

Literature cited

1) Aris, R.: Chem. Eng. Sci., 9, 226 (1959)

2) Brown, R. L. and J. C. Richards: Trans. Inst. Chem. Engrs., 38, 243 (1960)

3) Carberry, J.J. and R. H. Bretton: A.I.Ch.E. Journal, 4, 367 (1958)

4) Davidson, J. F. and D. Harrisson: "Fluidized Particles," p. 107 Cambridge, University Press, London (1963)

5) Edwards, M.F. and J.F. Richardson: Chem. Eng. Sci., 23, 109 (1968)
6) Evans, E. V. and C. N. Kenney: Trans. Inst. Chem. Engrs., 44, T189 (1966)

7) Gilliland, E. R. and E. A. Mason: Ind. Eng. Chem., 41, 1191 (1949)

8) —: ibid., 44, 218 (1952)

9) Hanratty, T.J., G. Latinen and R. H. Wilhelm: A.I.Ch.E. Journal, 2, 371 (1956)

10) Muchi, I., N. Morita, N. Mamuro, M. Nishibe and K. Matsushita: Preprint for Hamamatsu Meeting of The Soc. Chem. Engrs., Japan, No. 115 (1962)

11) Sinclair, R.J. and O. E. Potter: Trans. Inst. Chem. Engrs., 43, T3 (1965)

12) Urban, J. C. and A. Gomezplata: Can. J. Chem. Eng., 47, $353(1969)$

13) Yoon, S. M. and D. Kunii: Ind. Eng. Chem. Process Design and Development, 9, 559 (1970)

\title{
GAS ABSORPTION WITH CHEMICAL REACTION IN PACKED COLUMN UNDER ADIABATIC CONDITIONS*
}

\author{
KAKUSABURO ONDA, TAKESHI KOBAYASHI**, SHIGEO KATO \\ AND HIROSHI TAKEUCHI \\ Department of Chemical Engineering, Nagoya University, Nagoya, \\ Japan
}

\begin{abstract}
The absorption of carbon dioxide or sulfur dioxide into aqueous sodium hydroxide solution has been performed in a packed column, and its application to the theory of gas absorption accompanied by chemical reaction has been studied. Furthermore, the effects of the heat of solution and heat of reaction on gas absorption rate have also been investigated. The experimental values of reaction factor, which were evaluated from Eq. (7) by using the mean values of temperature and concentration at the top and the bottom of the column respctively, were in good agreement with theoretical values within an error of $30 \%$, even though the liquid temperature difference between the inlet and the outlet of the column was as high as $30^{\circ} \mathrm{C}$. Thus, the overall reaction factor in the packed column may be evaluated from Eq. (7) for other reaction systems.
\end{abstract}

A number of theoretical and experimental studies have been reported for gas absorption accompanied by chemical reaction in packed columns. Tepe and Dodge $^{10)}$ and other investigators ${ }^{1,6)}$ have studied the overall capacity coefficients in packed columns for the absorption of carbon dioxide into sodium hydroxide solution when the concentration in gas phase is less than several percent. Therefore, the variation. of sodium hydroxide concentration throughout the column is limited.

This paper discusses the absorption of pure carbon dioxide or pure sulfur dioxide by aqueous sodium hydroxide solutions in a packed column under adiabatic conditions. Furthermore, the effects of the heat of solution and heat of reaction on gas absorption rate are also investigated.

* Received on September 24, 1970

** Dept. of Ind. Chem., Suzuka College of Technology, Suzuka, Japan

\section{Experimental}

The absorption column used in this study was 7.6 $\mathrm{cm}$ I.D. glass tube and was packed with $6 \mathrm{~mm}$ ceramic Raschig rings to a maximum height of $40 \mathrm{~cm}$. The column consisted of a double tube evacuated and silver-coated like a vacuum bottle to avoid heat exchange through the column wall. Sodium hydroxide solution was irrigated on the top of the packed bed through a distributor with forty holes to obtain a uniform distribution. Exit liquid samples were withdrawn from the column through a sampling device fitted beneath the bottom of the packed bed to reduce the end effect. Gases of $99.8 \%$ purity were fed to the bottom of the column from commercial cylinders.

Inlet liquid temperature was adjusted to $15^{\circ} \mathrm{C}$. Inlet gas temperature was also adjusted to about $15^{\circ} \mathrm{C}$ except for a few runs. Inlet and outlet liquid samples were analyzed for concentrations of total alkalis and 